\title{
An Histochemical and Ultrastructural Analysis of the Dermal Chromatophores of the Variant Ranid Blue Frog
}

\author{
MICHAEL W. BERNS AND K. SHANKAR NARAYAN \\ The Department of Zoology, University of Michigan, Ann Arbor, \\ Michigan, and the Pasadena Foundation for Medical Research, \\ Pasadena, California
}

\begin{abstract}
Integument from blue and green areas of the variant blue frog were analyzed biochemically for pteridines and carotenoids. Solvent extraction and absorption spectrophotometry indicated that $\beta$ carotene was greatly reduced in the blue skin, and present in high quantities in the green skin of the blue frog. Thin layer and paper chromatography indicated that the pteridines were almost totally lacking in the blue skin, and present in normal quantities in the green skin of the blue frog.

Light and electron microscopy indicated that the xanthophore pigment cells were either greatly altered or absent from the blue integument and present in the green integument. The fine structure of the xanthphores of the green integument contained the normal ultrastructural components of xanthopores found in regular green integument. The blue integument contained an abnormal cell type that occupied the position in the dermal chromatophore unit normally held by the xanthophores. The possibility of these cells being abnormal xanthophores or some other cell type is discussed.
\end{abstract}

Blue pigmented variants in several ranid species have been recorded by several investigators (Berns and Uhler, '66; Martof, '62; Liu, '37). An adequate biochemical and morphological analysis of the integument of this variant form is lacking.

Recently Bagnara et al. ('68) defined the dermal chromatophore unit as the functional integration of several morphologically distinct cells which provides the organism with its total overall pigmentary effect. This unit consists of a layer of melanin containing melanophores, overlain by a layer of crystal containing iridiophores, which in turn, is overlain by a layer of carotenoid-pteridine containing xanthophores. Normal green coloration is probably caused by the crystalline iridiophore layer scattering whitè light up through the yellow xanthophore layer which filters out the blue wavelengths and permits the green to pass. A hypothesis of this nature was first suggested by Fox and Vevers ('60) and more fully defined by Bagnara et al. ('68). Furthermore, it was pointed out (Bagnara et al., '68) that blue pigmentation could be produced by leaching out the xanthophore pigments with alcohol.
The blue pigmentation in Rana could be explained by a lack of pigment from the xanthophores, or by a lack of the xanthophore cell type (Berns, '66). It is the purpose of this manuscript to examine the integument of the variant blue frog histochemically for the xanthophore pigments (carotenoids and pteridines), and morphologically for the xanthophores. The findings will be evaluated in light of the dermal chromatophore unit concept.

\section{MATERIALS AND METHODS}

Two blue specimens of Rana clamitans were used in these studies. Both specimens had blue and green areas in their integument. One specimen had a green mask (Berns and Uhler, '66) with blue pigmentation extending on the dorsal surface posteriorly from between the eyes to the anus. The other specimen was blue on the entire dorsal surface except for the dorsal surface of the legs, which was green. Samples of blue and green skin were removed from both specimens for the histochemical analysis. In the second specimen the $1 \mathrm{~cm}^{2}$ pieces of skin were cut in half, one half being used for histochemical analysis and the other half for morphological analysis. 
Analysis for carotenoids and pteridines was performed in a two-step process: the carotenoids were first extracted from the skin, and then the pteridines were extracted. The skin to be utilized for the chemical analysis was placed in a $37^{\circ} \mathrm{C}$ incubator immediately upon removal from the animal, and desiccated for one hour after which it was weighed to the nearest tenth of a milligram. The skin was next placed in $5 \mathrm{ml}$ of acetone $/ 5 \mathrm{mg}$ of dry skin weight and vigorously agitated with a glass stirring rod for 15 minutes. The acetone solution (which was yellow if carotenoids were present) was then placed in a spectrophotometer cuvette and the absorption curve run in a recording spectrophotometer. The absorption curve was then compared to a curve obtained from a pure sample of $\beta$ carotene.

After extraction of the carotenoids the same piece of skin was placed in a solution of $20 \% \quad \mathrm{NH}_{4} \mathrm{OH}$ in a concentration of $2 \mathrm{ml} \mathrm{NH} \mathrm{NH}_{4} / 2 \mathrm{mg}$ dry skin weight. All steps after carotenoid extraction were conducted in a dark room under safe light. The skin was left in the $\mathrm{NH}_{4} \mathrm{OH}$ for 24 hours to permit full extraction of the pteridines. After extraction the pteridine solution was subjected to thin-layer and paper chromatography. A $0.03 \mathrm{ml}$ volume of the pteridine solutions (from blue and green skin) was placed along the base of the chromatogram sheet approximately $2 \mathrm{~cm}$ from the bottom of the sheet, and $2 \mathrm{~cm}$ apart. The sheet was next placed in a solvent solution of $n$-butyl alcohol, acetic acid, and distilled water $(4: 1: 5)$, and run ascending for four to six hours. The chromatographic sheets were either no. 4 Whatman filter paper, or Eastman cellulose no. 6064 without fluorescence indicator. After removal from the solvent solution the chromatogram was air dried for ten minutes and then observed under ultraviolet light using a Wood's filter. The various fluorescent spots were noted with respect to $R F$ values, color, and relative intensity in comparison to standardized samples obtained from normal green skin. In addition, a pure sample of isoxanthopterin was run as a control.

The pieces of skin not used for the biochemical analysis were immediately fixed in $2 \%$ glutaraldehyde in phosphate buffer, washed in phosphate saline, post fixed in $2 \% \mathrm{OsO}_{4}$ in veronal acetate buffer, dehydrated in graded alcohol series containing uranyl acetate to absolute ethanol and propylene oxide. The tissue was infiltrated in Epon-Araldite and propylene oxide $(1: 1$, pure epon-araldite (overnight) and embedded in fresh plastic. Sections were cut on a Porter Blum ultramicrotome with a glass knife as thick sections for light microscopy $(1-2 \mu)$ and as thin sections (60$120 \mathrm{~m} \mu$ thick) for electron microscopy. Thick sections were stained with toluidine blue and mounted in permount. Thin sections were stained in uranyl acetate and lead citrate, and examined and photographed with an RCA EMU 3G electron microscope.

\section{RESULTS}

\section{Pteridine and carotenoid analysis}

Acetone extracts of green skin from both normal and blue frogs were always deep yellow in appearance. Extracts from blue skin were always colorless. Spectrophotometric analyses indicated that the extract of green skin had an absorption spectrum similar to that of $\beta$-carotene in acetone (fig. 1) with a broad band of absorption between 0.4 and $0.5 \mu$. The extract of blue skin by contrast exhibited no such absorption band.

Pteridine analysis also revealed distinct differences between the blue and green skin (table 1). Green skin always yielded three very distinct fluorescent spots whose intensity, color, and $\mathrm{Rf}$ values were similar in samples from both blue and green frogs. Comparison with published data suggested that the pteridines were AHP-6 carboxylic

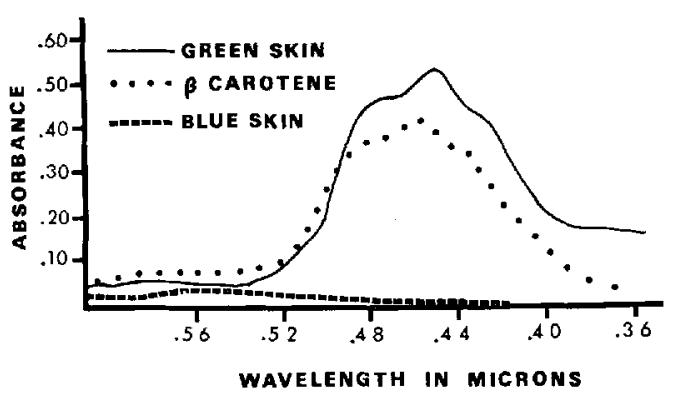

Fig. 1 Spectrophotometric readings on acetone extracts of blue and green skin from a blue frog. A pure sample of $\beta$ carotene in acetone is also indicated. 
TABLE 1

Chromatographic analyses of the pteridine content of shin

\begin{tabular}{|c|c|c|c|}
\hline \multirow{2}{*}{ Skin sample } & \multicolumn{3}{|c|}{ Fluorescent color, intensity ${ }^{1}$ and $\mathrm{RF}$ values } \\
\hline & Blue, $\mathbf{R f}$ & Purple, RF & Blue, $\mathrm{RF}$ \\
\hline $\begin{array}{l}\text { Blue frog } 1, \\
\text { green skin } \\
\text { Blue frog } 1\end{array}$ & +++0.40 & +++0.28 & +++0.19 \\
\hline $\begin{array}{l}\text { green skin } \\
\text { Blue frog } 1 \text {, }\end{array}$ & +++0.40 & +++0.29 & $+\frac{1}{i}+0.20$ \\
\hline $\begin{array}{l}\text { blue skin } \\
\text { Blue frog } 2\end{array}$ & 0 & + & 0 \\
\hline $\begin{array}{l}\text { green skin } \\
\text { Blue frog } 2\end{array}$ & ++++0.45 & ++++0.30 & ++++0.23 \\
\hline $\begin{array}{l}\text { blue skin } \\
\text { Green frog skin } \\
\text { Pure isoxanthopterin }\end{array}$ & $++\stackrel{0}{0.42}$ & $\begin{array}{c}0 \\
++++0.30 \\
++++0.30\end{array}$ & $\begin{array}{c}0 \\
++++0.21\end{array}$ \\
\hline & AHP-6 Carboxylic acid & Isoxanthopterin & Biopterin \\
\hline
\end{tabular}

${ }^{2}+$, weak fluorescence; +++ , moderate fluorescence; $+-1-++$, strong fluorescence.

acid, isoxanthopterin, and biopterin. The identification of isoxanthopterin was confirmed by running a pure sample of this compound on the chromatograph. Unlike the green skin, the blue skin demonstrated almost a complete lack of pteridines. The blue skin from the first frog yielded one very faint, questionable, blue fluorescent spot $(t)$ corresponding to isoxanthopterin. The blue skin from the second frog did not yield any fluorescing spots.

\section{Morphological analysis}

Light microscope examination of the sections indicated a profound difference between the blue and green skin. In both cases melanophores and iridiophores could be discerned in their normal configuration, i.e., iridiophores directly above the melanophores. In addition, the xanthophore layer was clearly visible in the green skin just above the iridiophore layer (fig. 2 ). In the blue skin there did not appear to be a clear contiguous xanthophore layer above the iridiophores (fig. 3). However, cells were visible between the iridiophore layer and the epidermis. These cells were in the position where one would expect to find the xanthophores, but they were not of the same appearance as the xanthophores of the green skin. Since it was difficult to draw any significant conclusions from the light microscopy, the skin was examined with the electron microscope.

Electron microscopy of the green skin from the blue frog yielded a picture of the dermal chromatophore unit similar to that presented by Bagnara et al. ('68); a lower layer of melanophores, a layer of iridiophores with the closely apposed xanthophores (fig. 4). The fine structure of the xanthophores appeared normal with the typically clear pterinosomes, and large carotenoid vesicles (fig. 5). The blue skin, however, contained melanophores and iridiophores in the normal configuration, and a cell type apposed to the iridiophores that did not have the fine structural components of normal xanthophores (figs. 6, 7). Neither pterinosomes nor carotenoid vesicles could be detected. Instead, these cells had inclusions that were electron dense and ovoid. These cells were always found just above (dorsal) and closely apposed to the iridiophores. Several different regions of the blue skin were sectioned and examined with the same results. These same cells were also found in the green skin where, however, they were very scarce, and always found below the melanophore layer.

\section{DISCUSSION AND CONCLUSIONS}

The great reduction (if not total absence) of the yellow pigments, carotenoids and pteridines, from the blue skin is the cause for the blue pigmentation. The relatively normal occurrence of these pigments in the green areas of the blue frogs demonstrates that the absence of these pigments is a phenomenon localized to specific areas of the integument rather than generalized to the whole organism. In addition, since specimens have been found 
with blue pigmentation virtually anywhere on the dorsal or lateral sides of the body (Berns and Uhler, '66) it does not appear that the same regions of the integument are always blue.

It is less easy to make absolute conclusions about the ultrastructure of the blue integument. It is clear that the xanthophore layer is greatly altered in the blue skin. Whether this reflects a complete absence of the xanthophore cell type or merely an alteration in the xanthophore fine structure can not be definitely stated. A cell type is found that has the anatomical position in the dermal chromatophore unit occupied by the xanthophores. However, this cell type has neither the pterinosomes nor the carotenoid vesicles normally found in xanthophores. Furthermore, the existence of normal xanthophores elsewhere in the blue frog integument (in the green areas), indicates that the normal xanthophore cell type is present in the frog. There are two possible explanations for the unusual cell type found in the blue skin: (1) it is either an immature or atrophied xanthophore, (2) it is another cell type (non-xanthophore) that has migrated into the region normally occupied by the xanthophores. The first alternative would be confirmed if there were some form of pterinosome, either partially formed, or even greatly altered, found in any of the cells examined. It might be suggested that the ovoid, electron dense bodies are abnormal pterinosomes. However, direct evidence for this is lacking. The second alternative, that another cell type has migrated into the xanthophore region, might be confirmed if the cell type were found elsewhere in the blue integument, and not just directly apposed to the iridiophores. Credence might be given to this theory because the unusual cell type is found (though rarely) in the submelanophore layer of the green skin. Again, direct evidence is lacking. Perhaps this question can only be resolved by studying the formation of the pigment pattern during embryogenesis and metamorphosis.

Whether the xanthophores are totally absent, or whether the xanthophores are present in an immature or atrophied form, the blue variant could be used as a tool to investigate xanthophore genesis, and the related synthesis and deposition of pteridines and carotenoids within the dermal chromatophore unit. The attainment of these goals relies upon the ability to have available embryos and tadpoles that will develop blue pigmentation. Breeding experiments between blue adults, and blue and green adults failed to yield blue offspring (Berns, '66; Nace and Richards, personal communication). If, indeed, the blue pigmentation is genetic (as has been tacitly assumed for many years), it appears that expression of the characteristic either does not follow simple Mendelian lines, or is greatly influenced by environmental factors (or both). Therefore, the establishment of a genetic strain of blue frogs, or even the assurance of a proportion of blue offspring per cross, is a necessary prerequisite to further studies on the blue-pigmented variant.

\section{ACKNOWLEDGMENTS}

The authors would like to acknowledge Dr, George Nace and Dr. Chris Richards of the Department of Zoology, University of Michigan, for supplying one of the blue specimens. In addition, we express our gratitude to Mr. Garbis Karimian and Mr. C. George Lefeber for preparation of the photographs. The pure sample of isoxanthopterin was provided by The Wellcome Research Laboratories, Burroughs Wellcome Co., Scarsdale, New York.

\section{LITERATURE CITED}

Bagnara, J. T., J. D. Taylor and M. E. Hadley 1968 The dermal chromatophore unit. J. Cell Biol., 38: 67-79.

Berns, M. W., and L. D. Uhler 1966 Blue frogs of the genus Rana. Herpetologica, 22: 181-183.

- 1966 Some genetic and histochemical aspects of the variant blue frog in the genus Rana, M.Sc. thesis, Cornell University, Ithaca, New York.

Fox, H. M., and G. Vevers 1960 The Nature of Animal Colours. Sidgwick and Jackson Lt, London.

Liu, C. 1937 The occurrence of blue frogs in the Peiping region. China J., 15: 248-249.

Martof, B. S. 1962 An unusual color variant of Rana pipiens. Herpetologica, 17: 269. 
PLATES 


\section{PLATE 1}

EXPLANATION OF FIGURES

2 Light micrograph of green skin. Note the three chromatophore cell types below the epidermis (E): $\mathrm{X}$, xanthophores with nuclei $(\mathrm{n})$; and dark cytoplasmic inclusions (ci); I, iridiophores with the lamellaelike appearance; and $M$, the dark melanophores. $\times 1000$.

3 Light micrograph of blue skin. Note the epidermis (E), and the normal looking iridiophores (I), and melanophores (M). The region normally containing the xanthophores appears markedly different, and contains a cell type that has the position of the xanthophores, but different morphology (Z). $\times 1000$. 
BLUE FROG CHROMATOPHORES

PLATE 1
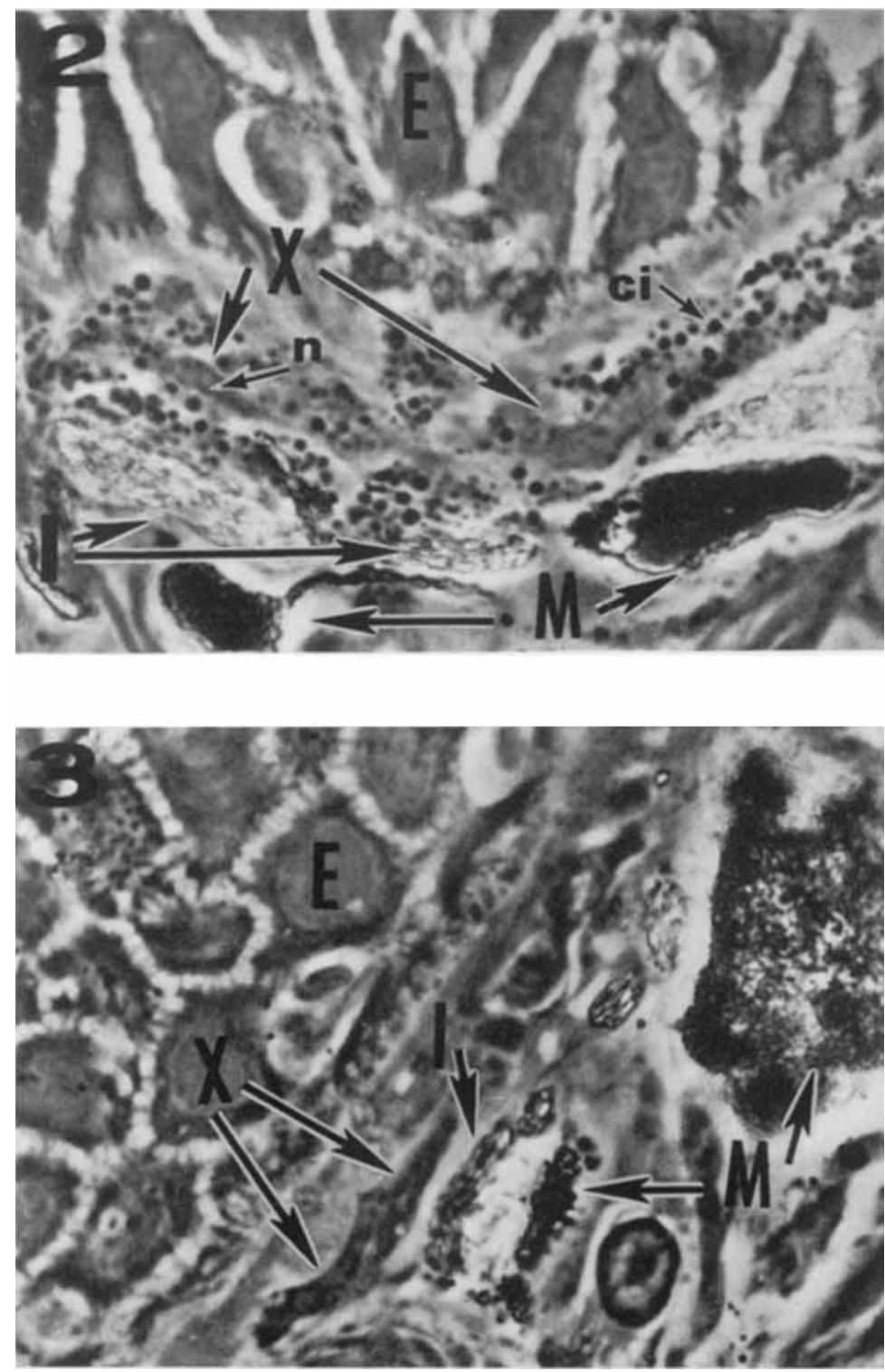
PLATE 2

\section{EXPLANATION OF FIGURES}

4 Electron micrograph of green skin (from blue frog) illustrating normal chromatophore morphology and location: $E$, epidermis; $X$, xanthophore; I, iridiophore; $M$, melanophore; CM, connective tissue and muscle. $\times 5,000$.

5 Electron micrograph of green skin illustrating the fine structure of the chromatophores: $X$, xanthophore; $P$, pterinosome; $c v$, carotenoid vesicles; $I$, iridiophore; $n$, nucleus; $M$, melanophore; $m$, melanosomes. $\times 25,000$. 

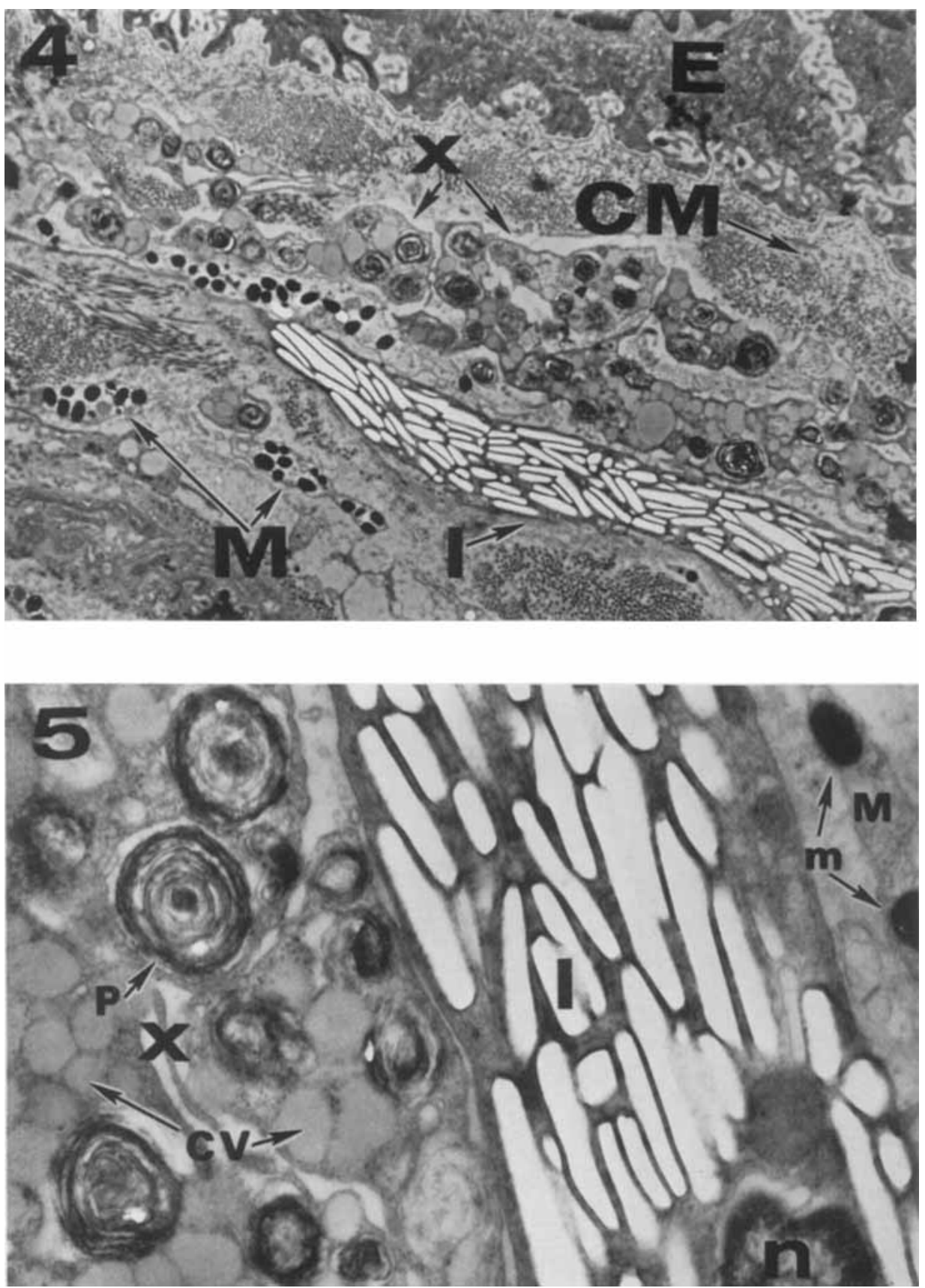
PLATE 3

EXPLANATION OF FIGURES

6 Electron micrograph of blue skin illustrating general location of chromatophores: E, epidermis; I, iridiophore; M, melanophore (not visible in this photograph, arrow indicates location); $\mathrm{Z}$, the cell type corresponding in position to the xanthophore; $C M$, connective tissue and muscle. $\times 6,000$.

7 Electron micrograph of the unusual cell type apposed to the iridiophore. Note the ovoid, electron dense bodies (od). Some appear to have thin membranes surrounding the most dense material, and one appears to be cut obliquely such that it appears to have a hollow internal structure $(h)$. These bodies could be abnormal pterinosomes. Mitochondria $(\mathrm{mi})$ are also visible, $\times 25,000$. 
BLUE FROG CHROMATOPHORES
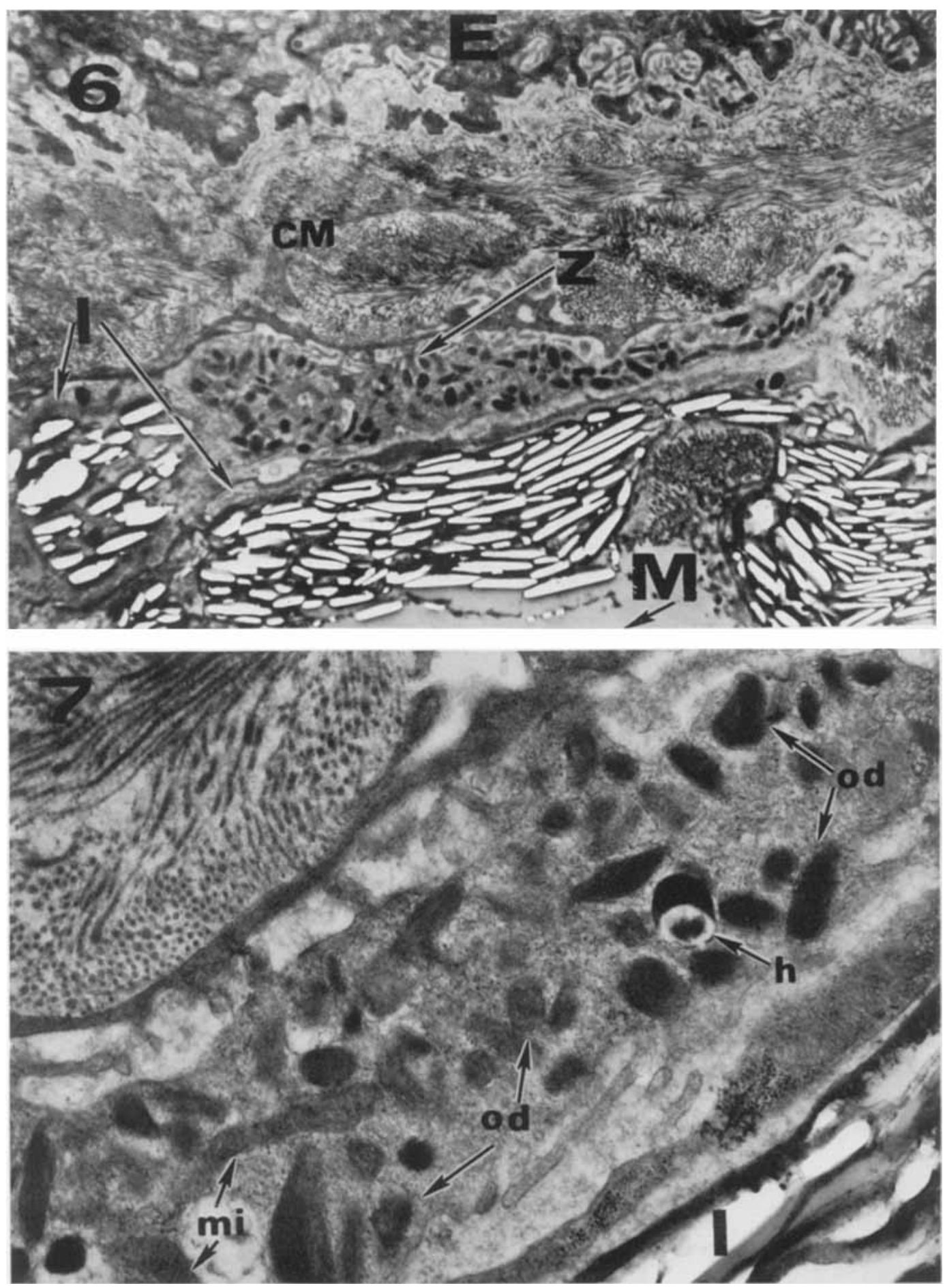